\title{
KEY FACTORS OF INFLUENCE IN THE PUBLIC PROCUREMENT PROCESS
}

\author{
Florin Emil MARDALE
}

\author{
National Defense University "Carol I" Bucharest, Romania \\ ec_mardale_florin@yahoo.com
}

\begin{abstract}
Public procurement is an important part of any economy, regardless of the geographical location, political orientation or level of development. Therefore, they can be considered as a separate part, but not insignificant, of the business of a functioning market economy. Moreover, they benefit from its own law, including the global economic agreements governing commercial transactions of this type. One of the most important goals of the activities of public institutions is to "deliver" to the taxpayer (in this sphere of beneficiaries of public services are included both individuals and legal entities) services of a quality as high as possible, trying to satisfy their requirements. With a strategic-military background in a rapidly changing context, institutions that are part of the national defense system, public order and national security, are faced today, seemingly more than ever with challenges increasingly vocal expressed, to supply services of personal security at a level and a quality that generates peace and calm of everyday life. We therefore believe that a pragmatic and realistic approach is required to procurement in military organizations, aiming goals and measuring results in a clear and precise manner.
\end{abstract}

Keywords: procurement, influencers, military organization, development, achieving performance.

\section{Introduction}

The whole process of procurement is to satisfy needs in the material assistance of public institutions the same as economic entities of private law. This approach records at the level of public bodies certain legal limitations and restrictions, causing different conceptual approaches. The main difference in the procurement of a good or service at a public entity consists of inflexibility of the system which no longer allows any corrections to the original conditions during the development of the process, unlike private operators who can shape their demand at all times, according to market developments and change of their needs. However, we believe that the principles of private economic operators should not be overlooked when seeking conceptual structure of a procurement procedure.

Overall, procurement process, as any economic activity, records during its course various influences, both positive and negative, leading ultimately to achieving the expected and less desirable results. These factors can be exogenous, i.e. political, economic, demographic, social and even military, but also endogenous, such as coverage of needs through the budget of an institution, the management strategy, the institutional structuring - command chain length, the degree of preparedness of personnel in leadership positions and those from the execution level.

\section{Factors with positive influence on the procurement of military organisations.}


Economic literature is not intended, apparently, in an exhaustive manner to achieve performance in public procurement, but only legal and budgetary constraints, although this area is very sensitive and constantly complained since it is subject to corruption. Certainly, the two areas mentioned (the legal and financial) are the fundamental aspects of analysis, but, furthering researches to the essence of activity, it inevitably reaches how to make this process efficient.

The public institutions in general and military organizations in particular have remained somewhat anchored to the past, meaning that all their problems' solutions are expected to be received from a higher level and own involvement tends to diminish.

The engagement of institutions to the outside economic environment, very vivacious and oriented at achieving quick results, driven largely by the effects of the economic crisis of recent years (which created a pronounced lack of liquidity) should be monitored at both central institutional and local levels. This area should be analyzed by the fact that the main buyers in the market are organizations financed from the state budget and the funds that they bring to the market are increasingly substantial (in accordance with the budget approved for 2016 expenditures for goods, services and capital expenditures exceed 2.2 billion EUR [1].

Among the determining factors, identified in the military organizations that influence in a considerable proportion the public procurement, there are: the political, economic, social factors and the institutional structuring, namely the length of the chain of command.

The influence of the political factor is crucial in public procurement processes since it is involved in all phases of the approval, validation and distribution of the funds needed to carry out specific procedures (approval of the state budget is the attribute of the Romanian Parliament, its validation is exercised by the President and the distribution of subordinate main credit release authority budgets is the task of the main credit release authority, for the institutions in the sector of defense, public order and national security, this is the Minister).

Creating the legal framework of activities of public procurement and supporting the institutional framework and resources needed to complete the public procurement processes are also attributions of macro-managerial level structures.

Political will can be imposed only after a validation process through the ,filter" of constitutional and legal provisions that may stipulate precisely the process of transformation of political views in policy decisions and then in legal rules, the only mandatory provisions in a public procurement activity.

The political factor can be an element of balance, because on the basis of a medium and long term forecast and strategy for carrying out procurement activities in all fields there can be provided essential information (allocating a certain percentage of GDP towards activities is a good example through which a long-term strategy in this area can be established).

The concept ,value for cash" [2] does not have to mean ,the lowest price", because it is recommended, in new EU legislation on purchases, to look for finding the optimal combination between total cost and required quality, so as to meet the needs of the purchaser. Therefore, we consider it necessary that in the procurement activity, contractors do not allow diminishing quality standards under an acceptable level only for obtaining a low price. The emergence of economic entities with Romanian employees, suppliers for military organizations that meet the quality standards required is a prerequisite for sustainable and quality development of society.

If by the beginning of the economic crisis, small and middle enterprises did not really participate in procurement procedures carried out by the contracting authorities; in 
recent years we have seen an increase in their interest in participating in such „economic competitions", because, as we said, public institutions become some of the most important sources of cash flow for the internal market of a country.

The social component of the public procurement system is essential within each national economy, because it tries to respond to certain public expectations, among which we can exemplify:

- Requirements made by the documentation of public procurement are relevant to a particular social group;

- The contracting authority took into account when determining the necessary good or service, all the social, economic and environmental benefits of this acquisition;

- The acquisition creates growth opportunities for certain groups or areas of activity;

- Requests of the purchaser are sufficiently well expressed to enable the widest possible participation in the procurement procedure;

- Requirements of the purchaser can create contests of solutions beneficial both to contracting authorities and suppliers, which may cause future growth and potential jobs.

Part of the social component is found also in military institutions, their employees representing part of the public system. Although they have specific responsibilities in the national defense system, public order and national security, they represent an important component of the public sector, due to education, way of work and clearly defined hierarchy in these institutions.

The main feature of military organizations remains structure, a clearly defined and respected hierarchy. This main feature is in fact one of the positive factors that influence public procurement, because the structure of marketing and purchasing, has a clear subordination, with no intermediaries in the chain of communication and the provisions of the commandant are transmitted on the shortest channel, being able to be in a very limited time.

Therefore, in military institutions, highly formalized, formal communication occupies the most space for communication. Within it, messages, channels, communication networks are predetermined and regulated by clearly stipulated norms in the military organization.

Downward communication is conducted from the upper levels to the lower, the promoters being the managers and receptors of communication their subordinates. Also specific to the military organization is that all communications pursue the compliance with the military structures' hierarchy chain, but when talking about procurement this segment is very short. This activity aims in the public procurement process, the following activities:

- transmission of orders, provisions and guidelines for implementation of organizational goals and strategies;

- supply of any information on the procedures and practices to be used in the procedures;

- the assessment feedback of the activities and results consistent with organizational objectives proposed.

An effective downward communication, during the conduct of procurement procedures, not only ensures the coordination and control of subordinates at the organizational level, but also allows the inter-structural interaction to establish the needs. The focus of downward communication only on the transmission of instructions and procedures, to the detriment of performance assessment and information on the reasons for performing certain tasks may have a negative organizational impact. Reassessment and reconstruction of military structures brought about changes in the management process, in terms of modernizing and adapting it to the requirements of Euro-Atlantic structures. 
In downward communication there can still be some problems regarding the disparity between what managers believe that they have communicated and what their subordinates believe they communicated. While managers perceive their posts as positive, subordinates tend to perceive them as indicators of management dissatisfaction in connection with their activity. Therefore, in our opinion, we consider it necessary that, especially for written communications, positive elements are emphasized in the same way as the negative elements. Also, in terms of the complexity of procurement processes, commanders must give particular importance to the feed-back of downward communication, not only to ensure its efficiency but also to involve subordinates actively in developing management activity across the organization.

On the other hand, upward communication is conducted from lower to higher hierarchical levels, having as initiator the subordinate and the manager as receiver. The main role is to ensure the feed-back through the following activities:

- preparation and submission of reports on activities at quantity, quality and regularity of obtained performance. These reports are required periodically by higher echelons and are considered very important in the communication flows of the military organizations;

- transmission of problems, critical issues that put subordinates in difficulty;

- submitting proposals for improvement of activity, allowing them to reflect and increase efficiency of activities;

- announcement of complaints and conflicts that exist among employees in order to solve them, because these problems can negatively influence the organizational climate.

The latter two issues special attention is given within the military organizations that provide monthly performance of balance sheet activities and of meetings without agenda on categories of staff, using the sense of belonging to a specific professional category as well as to facilitate free expression of problems. Reaction of military organization to any form of conflict is prompt, potential conflict being repressed at an early stage, especially through an approach like "authoritysubmission".

In our view, these positive factors of influence can always be considered of opposite influence, especially exogenous factors (political, economic, social) due to various influences that can be felt by them. Involvement and the creation of positive feedback regarding the work of military organizations should constitute an active influence of the public life in our society, with no need for unfavourable internal or external developments to the national security to pursue support activities or endowments through last minute solutions.

\section{Negative factors of the public procurement process in military organizations}

Like any economic process, the procurement in an organization suffers both positive and negative influences. Among the latter, we identified a series of influences, especially of internal origin, such as: coverage of needs of the institution by the allocated budget, management strategies and readiness of staff at managerial and at execution levels.

In recent years, due to the global economic crisis, suffered significantly by the Romanian economy, insufficiently developed to better cope with such a shock, there have been successive reductions in budget allocations for the institutions in the defense sector, public order and national safety. These budget reductions have caused an adverse effect on these institutions, both in terms of staff and in terms of current endowment and operating activity.

In terms of budgetary allocations, the situation within the National Ministry of Defence and Internal Affairs is the following: 
Thousands of lei

\begin{tabular}{|c|c|c|c|c|c|c|c|}
\hline \multirow{2}{*}{ Sector } & $\begin{array}{c}\text { Type of } \\
\text { expenditure }\end{array}$ & $\mathbf{2 0 1 0}$ & $\mathbf{2 0 1 1}$ & $\mathbf{2 0 1 2}$ & $\mathbf{2 0 1 3}$ & $\mathbf{2 0 1 4}$ & $\mathbf{2 0 1 5}$ \\
\hline \multirow{2}{*}{ Defense } & Staff expenditure & 2.705 .725 & 2.646 .082 & 2.918 .985 & 3.493 .232 & 3.113 .853 & 3.355 .114 \\
\cline { 2 - 8 } & $\begin{array}{c}\text { Material } \\
\text { expenditure }\end{array}$ & 554.302 & 463.175 & 508.036 & 482.590 & 526.423 & 715.314 \\
\hline $\begin{array}{c}\text { Public order } \\
\text { and national } \\
\text { security }\end{array}$ & Staff expenditure & 8.993 .208 & 8.250 .858 & 8.788 .507 & 10.262 .311 & 9.419 .618 & 10.449 .488 \\
\cline { 2 - 8 } & $\begin{array}{c}\text { Material } \\
\text { expenditure }\end{array}$ & 967.211 & 804.745 & 791.802 & 833.222 & 1.108 .234 & 1.073 .017 \\
\hline $\begin{array}{c}\text { National } \\
\text { budget }\end{array}$ & Staff expenditure & 16.899 .800 & 15.309 .517 & 16.384 .018 & 19.556 .298 & 17.081 .976 & 20.048 .007 \\
\cline { 2 - 8 } & $\begin{array}{c}\text { Material } \\
\text { expenditure }\end{array}$ & 3.727 .945 & 3.881 .386 & 4.178 .731 & 4.347 .558 & 4.417 .675 & 5.042 .804 \\
\hline
\end{tabular}

Table no. 1 - State budget allocations 2010 - 2015

(Source: the author, from the data available in the annual state budget for the years 2010, 2011, 2012, 2013, 2014, 2015)

As you it can be noticed, we have examined only two categories of expenditure, namely personnel costs and those for procurement of goods and services, since capital expenditures for investments are disparate, with no consistent investment program, available money occurring in general, by the end of the financial year.

Budgetary allocations for the provision of funds have had a discontinuous evolution in both structures analysed, following the trend imposed by the general consolidated budget. Certainly, this type of public expenditure is directly influenced by the number of indicators in payment, but also by the rights that are granted. Although the evolution of the number of employees of the ministries analysed were continuously decreasing, we can say that all positive corrections of the budgetary allocations were determined by updating values of offset amounts (like allowance of the norm of food, cash compensation of equipment norms) or the granting of new rights, especially to compensate for overtime work done on normal days or free ones.

At the amounts of money for procurement of goods and services shows that the trend imprinted in the generally consolidated budget has not been respected by the two ministries analysed in the allocations. Thus, allocations in 2011 have been reduced for the Ministry of National Defence (suffering a negative correction of $16.44 \%$ compared to 2010 ), so that in 2012 it received a slight increase, followed by a decrease again $(5 \%$ decrease of allocations in 2013 compared to 2012), finally, entering in the last two years in the budgetary logic of increase.

The amounts for material expenses have been successfully diminished to the Ministry of Internal Affairs, until 2013, when it entered an uptrend, following, as we said, the increase imposed by the state budget. Although they had an increasing character, however, these amounts have not reached the level had in 2010 in the five years analysed. Therefore, in 2010, the budget allocated to the Ministry of Internal Affairs for the purchase of goods and services was $25.94 \%$ of the state budget for the material acquisitions, the closest level recorded being in 2014 when the amounts provided amounted $25.09 \%$.

Another management component that negatively influenced the evolution of the procurement sector in the ministries mentioned above was the organizational strategy or more precisely the inconsistency of this component.

Since the institutions of this sector are analysed through a common budget line, as well as in terms of fiscal-budgetary view which includes all institutional components financed by the state budget, all the strategies adopted in terms of procurement and the achievement of actual objectives of training and equipment have been marked by fiscal austerity.

The current international conditions and NATO partners have imposed only in 2015, setting a minimum budget allocation 
of GDP, which could lead to establishing a long-term strategy to equip the armed forces.

Starting from one of the simplest definitions of strategy that appears when an "organization has a long-term goal, scheduled for precise and articulated that can be integrated into a coherent plan of action" [3] we consider it necessary that within the structures described there is a coherent plan of equipment and increase of armed forces capabilities. The existence of a strategic management would enable the formulation, implementation and evaluation of public procurement decisions at macromanagerial level so that subordinate institutions achieve the assumed long-term objectives. Strategic management enables military organizations to align their targets to the internal and external economic environment, also allowing the periodic evaluation of all the system's structures and capabilities that they have achieved.

In the military organizations' practice, the prioritization of organizational objectives was not used, to concentrate their resources for their successive accomplishment; moreover, it was not pursued if the correctness of decisions undertaken at macro-managerial level was well understood at operational level.

Strategic planning involves the development of an effective and coherent link between inputs and outputs, between effort and achievement and a realistic anchoring to external limitations at a certain moment. It attracts a regulation of the effort designed to lead the organization to adopt fundamental decisions on their implementation, aiming to clarify the organizational goals and objectives (which is the military organization's place in the public procurement market, what goals are pursued to be achieved in the organization, how are such activities are carried out, etc.).

Treated strategically, public procurement of military organizations must pursue the strategic, tactical and operational goals undertaken by the armed forces in international treaties, and the National
Defense Strategy of the Country, which provides for "ensuring human resources, material resources, financial and information resources necessary to maintain and develop the operational capacity of relevant institutions based on a rigorous planning process" [4].

A rigorous planning, in a budget covered at an acceptable level, requires a determination of the organizational mission, a goal setting, determination of options and a classification in reasonable strategic terms.

Strategic planning involves a concentrated action of the management and operational structures in all phases of this activity. Another negative influence on the military organizations regarding procurement was recorded in the degree of preparedness of the personnel involved in carrying out these processes. This was determined on one side by the high mobility of staff specialized in these functions and, on the other hand by the poor human resource management activity regarding selection and training in this field.

The evolution of labour mobility was influenced by several factors, namely:

- continuing restructuring and reorganization that creates pressure to lay off staff, and

- flow of foreign investment, generating employment, providing tempting opportunities at a certain time and the sector formed of small and medium enterprises, increasingly more present on the labour market.

As it can be seen from Table no. 2, the number of employees of the Ministry of Defense and Ministry of Internal Affairs continues to decrease. 


\begin{tabular}{|c|c|c|c|c|c|c|}
\hline Ministry & 2010 & 2011 & 2012 & 2013 & 2014 & $\begin{array}{c}2015 \\
\text { (November) }\end{array}$ \\
\hline MAN & 79.210 & 77.290 & 77.246 & 77.553 & 75.406 & 74.638 \\
\hline MAI & 147.822 & 134.168 & 136.848 & 136.261 & 133.602 & 132.682 \\
\hline
\end{tabular}

Table no. 2 - The situation of the number of employees in the Ministry of Defense and Interior in last 5 years

(Source: the author, from the public data of the Ministry of Labour, Family, Social Protection and Elderly)

Thus, a steady decrease since 2010 can be noticed at the Ministry of Defence, from 79.210 indicators under funding, to 74.638 indicators in November, 2015.

In real terms there was a decrease of 4.572 indicators, i.e. a decrease in the number of personnel employed by $5.77 \%$ compared to 2010 , a real problem in the current context of the acute lack of specialists in these fields.

The decline is even more pronounced at the Ministry of Internal Affairs, where, in the last five years there was a decrease of more than $10 \%$ of the employees, i.e. a decrease of 15.140 indicators.

This concerning fact, with long-term effects on the activity of institutions is due, in our opinion, on the one hand, to the suspension of making employments in public institutions and, on the other hand, to the decrease of attractiveness of these fields, further characterized by specific restrictions, but also by a low level of remuneration (it can be noticed that at one of the military institutions under study, at the level of tertiary credit release authority, in the last quarter of $2015,25 \%$ of senior executives was remunerated with the gross national minimum wage).

Causes that led to these dynamic processes (redundancy or employment) were complex, being recorded on several levels, but they could be grouped as follows:

- economic reasons (economic crisis, structural adjustment, structural imbalances and deficits, the history of evolution of labour structure);

- institutional causes (legislative shortcomings in granting certain rights, poor organization and low capacity to meet new economic challenges in institutions, weak institutional capacity to respond to the avalanche and diversification of problems that the employees face);

- formative educational reasons (reducing the level of qualification and competence of new graduates, lack of skills and a diminished ability to adapt to systems and privations and not least behavioural problems);

- social causes (job insecurity, insecurity of revenue that could be affected by massive decreases, significant decrease in the purchasing power of members of state organizations);

- governmental causes (poor management of the labour market in general and especially of human resources, especially in the area of public institutions).

Another problem felt was also registered in human resources management within military organizations due to, on the one hand, on the specific hierarchy, and on the other hand, on blocking the development of concepts related to staff management. Specialized structures remained anchored in the old paradigm, which targeted only employment of personnel in an organizational structure and pursuing the employment in all available positions from this structure.

The new definition of human resource management activity aims at the evolution in this area from a macro perspective and involves organizing collective relationships between the management and the operational structure, strengthening interpersonal relationships and sketching new motivational perspectives. 
However, some of the weaknesses highlighted can be adjusted in such a way that organizational outcomes tend towards those proposed. In our opinion, regular assessment activities can cause structural or relational changes in organizations, in a manner that generates achieving the proposed performance.

\section{Conclusions:}

For a positive influence on the determinants of public procurement in military institutions there are several challenges, among which we can mention:

- high knowledge of the managerial system and the degree of resistance to change it;

- analysis, based on updated economic data of these factors;

- manner and extent of the influence of these factors on the various phases of the procurement process;

- organizational systems' modeling capability of these factors in the current socio-economic context.

The whole process of modeling requires coordination of several methods, multilevel, because the factors influencing the procurement economic processes also present a concerted action rather than disparate.

In a competitive economy many individuals, groups or private sector organizations (including chambers of commerce, professional associations and multinational companies) are actively involved in the public procurement market, becoming so-called "interest groups". Having different objectives and belief, these interest groups are involved in the public procurement system at several levels, starting from influencing the approval of certain legal provisions, to their implementation and influence of the budget's level of a particular sector. The public debate on the need to pay a certain percentage of GDP to the armed forces was visible, starting since the approved budget for 2016. Of course, the government program is a compromise between different views of interest groups, public policies and government strategies. In a democratic environment, cases of national consensus are recorded to adopt a particular program (as it was for the allocation of $2 \%$ of GDP to the army's budget, for a period of 10 years starting from 2017). In literature, when politicians, technocrats (bureaucrats) and interest groups work together to achieve a common the term used is ,iron triangle" [5], being very popular in the USA in the military procurement sector.

The influence in the USA of these "iron triangles" causes an increased speed in carrying out public procurement processes in the military field, producing a reduction in the time recorded since the approval of the acquisition until its completion.

With the adoption last year of the country's National Defense Strategy, the programmatic framework necessary to the development of such "centres of power" was created that can lead to developing coherent strategies for purchasing and equipping military organizations.

Success or failure in an economic competition to win a public procurement contract can have major effects on a company that competes on the free market.

The role of politics and its influence should be an element of balance, because it has the power to impose certain winners on a market, and this may lead to the elimination of competitors from the market, subsequently generating macroeconomic imbalances (in the absence of real competition). For large firms it is easy to make lower profits or even losses in the public contracts in order to present the best offer in economic terms, pursuing however the dissolution of competition.

Following macroeconomic aspects of the business, in order to sustain current economic growth recorded, in our opinion, public institutions should prefer local or national suppliers over those from outside the country. It is still being registered a 
major external pressure, especially regarding environmental issues and international agreements signed and assumed by our country (GPA - Global Procurement Agreement - issued by the World Trade Organization).

Environmental issues have become increasingly important in the trade and international production, implicitly in procurement, pursuing, like any other transaction process, to target elements of environmental protection, although they generate increases in costs. In our opinion, it would be preferable for local producers to readjust rapidly, adopting specific requirements, becoming important suppliers for military organizations.

Public procurement system records also the cultural and technological influences. It is possible, being considered by experts an extremely sensitive issue that in a culture, giving gifts or small gifts to be an accepted practice of institutional networking, and in this situation the operation of differentiating traditional gifts to the one designed to influence a certain competitive approach becomes very delicate. Although in our country this was a common practice, though unrecognized by anyone, it is attempted to impose legal provisions to remove any doubt that could be posed to any procurement operations.

In the last years, technology has been increasingly affected military institutions, forcing them to adopt new and practical technical methods. Therefore, faster adoption of electronic purchasing and payment systems as well as accessing specific online platforms, must be a priority for any military organization.

All such factors interact constantly with each other, turning into the key elements of public procurement activity, providing constant and dynamic challenges for the specialists in marketing structures. They find themselves permanently faced with the adoption of important decisions, being obliged to find always the best solution for the institution.
To better prepare them, we propose the adoption and implementation of measures aimed at creating a unified and coordinated training framework and the faster dissemination of data held by specialists, using the following directions:

- developing methods to assess the current trends in the techniques, tactics and strategies employed in this sector;

- support and development of publications that can communicate both to the general public and specialists the results of the research in public procurement, but also specialist technical information necessary for the development of this activity;

- developing a platform that includes data and results in the activity by professionals involved in marketing and procurement departments of military organizations;

- developing training programs of academic standards to which all those involved in public procurement should be required to take part in.

Modelling influence factors is a complex process whose finality can not be determined independently, but through an accumulation of results found in the activity. Thus, for public procurement, a concrete and practical assessment tool is determining the size of the budget allocated to this activity and comparing the degree of endowment of an institution at the beginning and end of a financial year. Benefiting from a political-military context favourable to endowment development, budgets allocated to institutions of the national defense system, public order and national security show a positive development, but which must be correlated with price developments in the national economy.

Military organizations must develop their high absorption capacity of funds, in terms of performance, based on strategic and operational well founded plans.

Setting well-defined, phased targets, and the pursuit thereof, shall constitute a 
basic element of any successful management strategy. Performance measurement of endowment activities and objective evaluation of results are mandatory steps in achieving organizational goals. These goals can be achieved through continuous evaluation of the existing status quo but also by a profound understanding of phenomena and specific challenges of the current context.

As we have remarked, public procurement processes of military institutions become more deeply rooted in social, economic, political and military conditioning of the global reality.

The effect of political factors, influenced more or less by national, and global, economic development, which aims to create the institutional framework for sustainable and future development, is felt more strongly, including in the public procurement field.

With a high degree of positivity in collective perception, military bodies record requests for the provision of high quality services, based on the legitimate needs caused by the increasingly uncertain and unstable international situation.

Under these circumstances public procurement must pursue the achievement of current objectives that will however suffer increasingly rapid changes, depending on the evolution of security environment. Therefore, we propose the development of platforms and publications in electronic media that can allow both internal posting and easy access to them. We also believe that institutions should increase attention on the preparedness of procurement specialists to benefit from competitive and timely services of some true professionals.

Therefore, military structures should develop their ability to operate in a pragmatic and effective manner, in a changed paradigm, able to offer solutions to the new challenges of the security environment.

\section{References}

[1] Legea nr. 339/2015, Legea bugetului de stat pe anul 2016, publicată în Monitorul Oficial nr. 941/19.12.2015, Anexa nr. 1.

[2] http://www.scotland.gov.uk./resource/doc/1265/0009333.pdf accessed on the $13^{\text {th }}$ of July, 2015.

[3] http://www.saylor.org/books/Principles of Management, p. 12, accessed on the $28^{\text {th }}$ of October, 2015.

[4] www.presidency.ro - Strategia naţională de apărare a ţării pentru perioada 2015-2019O Românie puternică în Europa şi în lume, p.20.

[5] Khi V. Thai, Challenges in public procurement pe www.unpcdc.org/media/4899 accessed on the $15^{\text {th }}$ of November, 2015. 